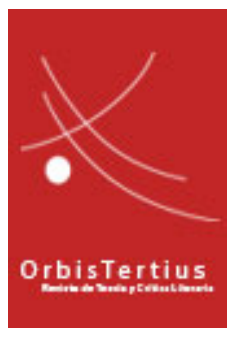

Orbis Tertius, vol. XXIII, n 28, e091, diciembre 2018. ISSN 1851-7811

Universidad Nacional de La Plata

Facultad de Humanidades y Ciencias de la Educación

Centro de Estudios de Teoría y Crítica Literaria

\title{
Libretas de un escritor viajero: Saer como naturalista amateur
}

\section{Carolina Maranguello*}

* Universidad Nacional de La Plata, Argentina

Cita sugerida: Maranguello, C. (2018). Libretas de un escritor viajero: Saer como naturalista amateur. Orbis Tertius, 23(28), e091. https://doi.org/10.24215/18517811e091 


\title{
Libretas de un escritor viajero: Saer como naturalista amateur
}

\author{
Carolina Maranguello \\ (Universidad Nacional de La Plata, Argentina)
}

\begin{abstract}
Resumen:
En este artículo se analizarán las libretas que Saer llevaba en sus viajes por Francia y Latinoamérica pero que utilizaba fundamentalmente para apuntar sus regresos al pais, desde 1982 hasta el año 2002. Tanto al hacer anotaciones sobre aspectos observados del paisaje como durante las notas preparatorias para futuros ensayos, Saer cita y reescribe las imágenes y las codificaciones de otros viajeros que tempranamente formalizaron el paisaje del Rio de La Plata. Interesará pensar qué operaciones y modos de observación practicados por estos exploradores retoma Saer y cómo los reescribe en función de su propio proyecto escritural e indagar cómo trama su regreso a la 'zona' autofigurándose como un naturalista amateur que dialoga fundamentalmente con William Hudson.

Palabras Clave: Juan José Saer, libretas de viaje.
\end{abstract}

\section{Abstract:}

This article analyzes the notebooks that Saer wrote during his trips to France and Latin America, but in which he also recorded his return journeys to Argentina, from 1982 to 2000. Both in his notes on particular aspects of the landscape as well as on his preparatory notes for future essays, Saer quotes and rewrites the images and codifications of other travelers who had early pictured the landscape of the Rio de La Plata. The focus will be put on the literary devices and modes of observation of the explorers Saer takes up and on how he rewrites them according to his own scriptural project. Moreover, we will investigate how Saer configures his return to the 'zone' as an "amateur naturalist" who dialogues primarily with William Hudson.

KEYWORDS: Juan José Saer, Travel Notebooks, Return Journeys, Naturalism .

Desde 1982 hasta el año 2002, Saer viaja acompañado de unas pequeñas libretas en las que apunta sus desplazamientos por Europa y América Latina. ${ }^{1}$ Sin embargo, a pesar de incluir algunas de las reflexiones y sensaciones que le disparan los espacios desconocidos, las entradas más abundantes y frecuentes se realizan sobre sus viajes de regreso a Argentina, que el escritor comienza a realizar desde 1982, después de seis años de ausencia. $^{2}$ Utilizadas en general para la anotación en vivo, estas libretas acopian una gran cantidad de apuntes y bocetos e incorporan los más diversos tipos textuales: instrucciones de escritura, citas, pensamientos, borradores de poemas y de cartas, observaciones botánicas y registro de modismos del habla rioplatense, impresiones urbanas, notas preparatorias para novelas y ensayos.

Interesa entonces recuperar estas libretas de viaje que permanecieron inéditas hasta su publicación en el segundo tomo de los Papeles de trabajo $(2013)^{3}$ y cuya productividad no ha sido del todo abordada por la crítica, más allá de la excelente introducción de Sergio Delgado. Estos textos resultan claves para comprender cómo se transforma la idea de "zona" ${ }^{4}$ en la producción tardía del escritor, aspecto que se precisará al final del trabajo; permiten considerar autofiguraciones más inusuales que Saer ensaya en sus libretas y prueba también en sus novelas y ensayos y contribuyen, por último, a establecer linajes menos explorados entre su obra y la extensa biblioteca de viajeros que alimentan buena parte de su escritura.

Como podrá observarse, las libretas devienen un residuo de anotaciones e impresiones a las que Saer siempre regresa para confirmar alguna apreciación sobre el paisaje, pero sobre todo para advertir que las percepciones, ideas y asociaciones que le trae regresar al país ya las había anotado previamente, y más de una vez, en sus cuadernos de viaje: "y, como de costumbre, al sacar la libreta de apuntes para anotar en ella [...] algún pensamiento inédito, he descubierto que ya lo había consignado en algún viaje anterior" (Saer 2003: 21). Carácter paradojal de una escritura que, destinada a captar lo imprevisto y lo inédito, parece haber ya 
sido escrita. Este aspecto iterativo no sorprende en el proyecto literario saeriano y permite incorporar estos textos al resto del corpus que también se desarrolla a partir de reiteraciones y variaciones.

En diferentes oportunidades, tanto al tomar apuntes sobre aspectos observados del paisaje como durante las notas preparatorias para futuros ensayos, Saer cita y se apropia de las palabras e imágenes de otros viajeros, topógrafos y naturalistas que tempranamente recorrieron y formalizaron el paisaje del Río de la Plata. Interesará en primer lugar pensar con qué operaciones, imágenes y modos de observación practicados por estos exploradores dialoga Saer y cómo los reescribe en función de su propio proyecto escritural. En segundo lugar, se intentará indagar cómo trama su regreso a la zona autofigurándose como un naturalista amateur que retoma fundamentalmente a William Hudson. En este sentido, se buscará reflexionar de qué manera Saer podría integrarse a ese linaje de poetas-naturalistas que abre Hudson en Argentina y continúan poetas como Juan L. Ortiz, en tanto ofician como escritores excéntricos en medio de metrópolis culturales que regresan de diversas maneras a la pampa sudamericana; y como naturalistas amateurs que retoman y a su vez desarticulan el naturalismo practicado por viajeros como Azara, Darwin o Humboldt.

\section{LA HISTORIA NATURAL: LENGUA FRANCA}

Como señala Foucault en Las palabras y las cosas, "la historia natural no es otra cosa que la denominación de lo visible” (2013: 148) y el naturalista es, según Linneo, "[quien], 'distingue por la vista las partes de los cuerpos naturales, los describe convenientemente según el número, la figura, la posición y la proporción, y les da nombre"' (2013: 178). Efectivamente, en muchos de los pasajes que encontramos en las libretas, Saer se encarga de nombrar a las especies vegetales y animales que se cruza en los diversos desplazamientos que realiza por paisajes urbanos y naturales, adosándoles su nombre científico y describiendo con exactitud las ocurrencias cromáticas de flores y pájaros. En una entrada de las libretas puede leerse por ejemplo la siguiente anotación: "Retama amarilla: Fam. Leguminosas Spartium junceum" (Saer 2013:290), un resabio linneano de clasificación botánica que puede, en principio, sorprender pero que paulatinamente se vuelve parte de un fragmentado diario de naturalista que Saer va incorporando en sus libretas. ${ }^{5}$

El "visible" constituido por la historia natural, continúa explicando Foucault, tenía sus limitaciones y restricciones formales. En primer lugar, durante el siglo XVII se subordinan los sentidos de la percepción al sentido privilegiado de la vista y se restringe su dominio a la faz superficial, por lo cual sólo era posible describir a los seres vivos a partir de 'objetos filtrados': líneas, formas y relieves, un tipo de composición que incluso desestimaba la importancia del color como elemento útil. En segundo lugar, la historia natural se caracteriza por suturar el hiato entre las palabras y las cosas a partir de una red precisa de nombres, una clasificación que "vuelve visible" la naturaleza a partir de la conformación de un "sistema" que reúne en una serie de rasgos limitados las constantes y las variaciones de las especies. Foucault establece relaciones entre la historia natural y el lenguaje: "la historia natural es contemporánea del lenguaje, [...] fija los elementos comunes e impone, por último, los nombres. Clasificar y hablar tienen su origen en ese mismo espacio que la representación abre en el interior de sí misma” (2013: 176).

Si la literatura de Saer puede ser leída como una insistente problematización de lo real y un trabajo exhaustivo y experimental sobre ese hiato existente entre mundo y lenguaje, podría parecer extraño en principio esa irrupción naturalista y ese afán por nombrar y clasificar que atraviesa su escritura. Un sugestivo fragmento de El río sin orillas acerca algunas claves para comprender este afán taxonómico:

El inmenso obelisco de cemento que adorna [la avenida Corrientes] no constituye para mí su atracción principal, sino los palos borrachos (choricia speciosa), con sus troncos inflados y espinosos de un verde claro, árboles de los que no he podido todavía, mediante la observación directa, deducir el ciclo de floración, ya que he visto ejemplares florecidos en diferentes épocas del año [...] lo que confirma una anotación anterior en mi libreta de apuntes: ‘ 4 de abril. Av. 9 de Julio a las 11.45 . En taxi. Palos borrachos florecidos (rosa, blanco, marfil). Acacias o tipas muy verdes todavía' [...]. En las ciudades del litoral [...] tres grandes árboles se disputan el estrellato estético cuando avanza la primavera, y florecen en este orden: el lapacho, cuyo 
nombre científico se me escapa, la acacia amarilla, lo bastante frecuente en Europa como para que el nombre latino que la identifica merezca ser mencionado, y el jacarandá o jacarandá mimosifolia... (Saer 2013: 26-27).

El primer gesto de Saer es correr la mirada del ícono turístico de la ciudad capital -el Obelisco- para centrar su atención en la variedad de árboles que crecen en Avenida Corrientes. Como él mismo lo explica en la introducción, El río sin orillas fue un libro por encargo dirigido principalmente a lectores europeos, por lo tanto el escritor se ve en la necesidad de explicar algunos rasgos del paisaje rioplatense que serían evidentes para el lector argentino. ${ }^{6}$ En este sentido, la incorporación de la clasificación linneana parece funcionar como una lengua franca que comparten sus lectores americanos y europeos, porque como señala Foucault, por sobre la lengua cotidiana, la historia natural construye un edificio lingüístico en segundo grado en el que reinan "los Nombres exactos de las cosas", un lenguaje que no le deja lugar a la incertidumbre y desplaza hacia los márgenes de la "litteraria" 7 todo lo que se imaginaba y se fabulaba, los saberes populares sobre el objeto. Así se entiende, en primera instancia, la inclusión de los nombres latinos de las diferentes especies de árboles, una taxonomía dirigida al parecer para los "lectores idiotas" -así los llama-, en el sentido de "profanos". 8

La inclusión de la taxonomía linneana se justifica de este modo en el prolongado ensayo que le dedica al Río de la Plata, aunque resulta un tanto más enigmática en una libreta cuyo destinatario era el mismo escritor. ${ }^{9}$ En varias oportunidades será él quien busque, mediante la observación directa, determinar el ciclo 'anómalo' de floración de los árboles mencionados, autofigurándose como un naturalista amateur que exhibe en sus libretas las deducciones que saca y el proceso mediante el cual se apropia del vocabulario científico: "braquicéfalo=de cráneo redondo/ Dolicocéfalo= de cráneo ovalado" (Saer 2013:298). Sin embargo, como se verá, la operación naturalista ensayada ocasionalmente por Saer excede y problematiza ese "visible" restringido y esa lengua "neutra" de la historia natural para incorporar y traer a un primer plano eso que había quedado desplazado por la taxonomía linneana (la "litteraria"). Saer no persigue ningún interés utilitario cuando identifica plantas y animales o determina ciclos de reproducción y floración. Pero hacerlo, incluso obsesivamente, le permite refundar las coordenadas espaciales y temporales del paisaje natal.

En el ya clásico texto Travel as metaphor, Georges Van Den Abbeele señala que el viaje presupone que hay algo que permanece: un oikos, una casa que define y "domestica" lo indeterminado del viaje. Sin embargo, advierte, el punto de partida nunca es igual al punto de retorno, y ese oikos, paradójicamente, puede provocar una gran desorientación una vez que se ha producido el desvío del viaje. Las libretas de Saer revelan la diferencia del oikos y muestran qué sucede cuando el espacio natal se convierte, a partir de una "perspectiva exterior", en otro viaje hacia lo "desconocido".

¿Hasta qué punto entonces no podría pensarse que las incursiones de Saer en el territorio argentino reescriben, en clave de exilio, el afán de conocimiento y apropiación que guió a los demarcadores, geógrafos, naturalistas y militares que transitaron, midieron, clasificaron y nombraron los accidentes geográficos del Río de la Plata, pero también sus ocurrencias astronómicas, climáticas, animales y vegetales, ya no para usufructuar económica y militarmente el territorio sino para seguir reescribiéndolo en clave íntima y ficcional? La contemplación "naturalista", como se verá, constituye una forma de volver a calibrar la percepción sobre la flora, la fauna y los fenómenos meteorológicos de la región sobre los que nunca dejará de escribir.

\section{Otro naturalista en el Plata}

En "La perspectiva exterior", el conocido ensayo cuyas notas preparatorias aparecen en la segunda libreta de viaje (la "Libreta II. Agenda 1989"), Saer postula que es precisamente esa "perspectiva exterior" el modo en que la cultura argentina se relaciona con Occidente pero también la mirada que moldeó las primeras impresiones sobre nuestro paisaje:

Esa literatura de viajeros es contemporánea a la aparición misma del país [...]. Félix de Azara, Millau, Mac Cann, Woodbine Hinchliff, Alfred Ebelot, [...] Albert Londres, el incomparable W.H. Hudson, que idolatraba hasta nuestros peores defectos, 
los mismos que también a Borges le parecen virtudes, han sembrado de imágenes y experiencias argentinas varios idiomas del mundo (Saer 1998: 20).

Interesa particularmente esta mención de Hudson porque es el escritor que mejor representa esa mezcla de poesía y naturalismo aficionado que también probará Saer en sus regresos al país y además porque es el viajero que aparece explícitamente mencionado en sus libretas así como en las notas preparatorias para novelas como La grande. En varias oportunidades, Saer sigue sus huellas. Constata en sus propios recorridos observaciones del escritor: "En el peaje cerca de Zárate, los aguaciles que se adelantan a la tormenta, de los que habla Hudson” (Saer 2013: 312), ${ }^{10}$ o lo incorpora como instrucción de lectura y escritura: "El domingo, la bandada de pirinchos, entre los árboles, el suelo, etc., contentos a causa del buen tiempo. (Ver Hudson). Las corbatitas, El benteveo” (Saer 2013: 372).

Según Carlos Gamerro en "Hudson y la invención del paisaje”, el escritor supo detenerse en el paisaje de la pampa y derramar una mirada minuciosa sobre plantas y animales, una verdadera "contemplación" que puede hallar como único ejemplo comparable en Argentina la poesía de Juan L. Ortiz. ${ }^{11}$ En Ficciones culturales y fábulas de identidad en América Latina, Graciela Montaldo ha señalado a su vez que la figura de Hudson fue dos veces retomada en la cultura argentina. En primer lugar, fue leído a principios del siglo XX como parte del acervo tradicionalista del "pasado nacional" y cronista de una vida rural no contaminada por la inmigración y la vida urbana. Esa perspectiva cambió durante el debate sobre la cultura nacional que se produjo en torno al peronismo. Hudson quedó desplazado a un plano borroso de la literatura argentina después de los cincuenta y "excepto por la relectura crítica que hace Martínez Estrada (Hudson como literatura argentina de resistencia) y por la reescritura muy mediada que hace Borges de algunos procedimientos, no volverá a ser incorporado más que esporádicamente" (Montaldo 2004: 136). Sin embargo, podríamos encontrar también, en la doble estela con que la crítica caracteriza a Hudson, 'poeta y naturalista', a Saer quien, como se sabe, también ha reconocido como maestro al poeta entrerriano y es un gran lector de las operaciones críticas de Martínez Estrada y de Borges. ¿Qué linajes comienzan a armarse o a enriquecerse si conectamos el paisaje de Saer ya no solo con el enigmático detenimiento de Juan L. Ortiz sino también con el activo, ${ }^{12}$ y un tanto melancólico deambular de Hudson?

"Perhaps I may say that my life ended when I left South America", reconoce Hudson en una entrevista hecha por Mosley Robert en su biografía. Hijo de una pareja de colonos norteamericanos radicados en el Río de la Plata durante los tiempos de Rosas, Hudson vivió en la llanura desde 1841 a 1874, aprendió a observar la naturaleza vagabundeando por el campo y abandonó voluntariamente América para adoptar su nueva patria cultural en Londres, desde donde se dedicó a escribir sobre esa experiencia fundante. Salvando las distancias, la trayectoria vital e intelectual de Hudson puede ser parangonada a la de Saer: ambos se autoexilian, más o menos a la misma edad y escriben desde Europa textos que no dejan de evocar las tierras en las que vivieron durante su infancia y juventud. Ambos son, de alguna manera, escritores "excéntricos" que escriben desde metrópolis culturales - el Londres del capitalismo imperial y el París de la vanguardia estética y política- sin asimilarse a ellas y vuelven el margen cultural y lingüístico en el que encuentran una zona de productividad estética y de resistencia política. ${ }^{13}$ Ambos son, a la vez, científicos amateurs (particularmente Hudson) y escritores de ficción, ${ }^{14}$ que retoman y a la vez se distancian del naturalismo practicado por científicos como Darwin, Humboldt o Azara. ${ }^{15}$

Saer parece mirar, por momentos, a través de los ojos de Hudson, quien -como ha señalado Fermín Rodríguez- captura jirones de percepción, formas que se hacen y se deshacen en la llanura. En Allá lejos y hace tiempo, una extensa memoria sobre su infancia y juventud en Argentina evoca el deleite físico y espiritual que sentía por el mundo visible y la comunión casi mística que experimentaba con la naturaleza. Los recuerdos de experiencias y personajes de su infancia así como las manifestaciones más íntimas de su vida anímica -sus tribulaciones religiosas, el afecto que sentía por su madre- conviven y se amalgaman muy bien con la incorporación de los nombres científicos y las descripciones de algunas especies vegetales y animales de la pampa, y su uso de la nomenclatura linneana es bastante similar al practicado por Saer: le sirve en general para alertar a sus lectores ingleses sobre las particularidades de la naturaleza americana así como para establecer 
comparaciones con especies animales y vegetales por ellos conocidos. Se trata, como también aparecerá en Saer, de un naturalista atento a los matices cromáticos y a los cambios lumínicos. En El naturalista en el Plata se puede leer por ejemplo: "Gynerium argenteum (cortadera) [...] cuando la luz atenuada da aspecto de vaga neblina a los profusos penachos, el viajero no puede menos de imaginar que esos matices tan variados son debidos a los rayos horizontales del sol o al reflejo de la vaporosa niebla del crepúsculo" (Hudson 2010: 13). Saer señala a su vez: "En Entre Ríos, el miércoles, por el camino de tierra, cruzó un cuis. Pelambre entre azulada y verdosa, entre acero y bronce" (2013:287). La anotación, que podría ser un haiku, captura un escenario y fija allí una brizna de acontecer. El boceto tomado del natural intenta reproducir la mutación cromática que experimenta el pelaje del animal mientras cruza ante los ojos del observador y reaparecerá, con mínimas variaciones, en La grande.

A medida que se desplaza por la ciudad o viaja entre los pueblos linderos de la zona, Saer inscribe, como se dijo, la multiplicación azarosa de animales y plantas. Lo que en los naturalistas anteriores es garantía de conocimiento verdadero y recopilación interesada para futuros trabajos de explotación económica, en Saer deviene escritura del tiempo y práctica demarcatoria: son los momentos en que florece un árbol, se reproducen ciertos peces o migran los pájaros los que proveen las marcas temporales y espaciales para situar los derroteros del escritor por la región. Saer no escribe un diario de viaje convencional, escandido por las travesías marítimas o las distancias recorridas en tierra, sino un fragmentado libro de apuntes cuya temporalidad la dan los ciclos naturales de reproducción y floración o las modificaciones climáticas significativas que anuncian los cambios de estación. ${ }^{16}$ Abundan además las anotaciones en las que Saer señala la presencia de determinados árboles en lugares característicos de la ciudad como el Parque España, la plaza o el Convento, como si el escritor pudiera trazar un mapa botánico del espacio urbano cuyos mojones serían los palos borrachos, los pinos, los jacarandás en flor y las araucarias. La historia natural se vuelve, como señala Natalia Brizuela en Fotografia e imperio, una nueva manera de construcción del espacio, señalamiento que ella hace para el momento en que la disciplina se consolidaba a comienzos del siglo XVIII pero que se manifiesta también en la versión libre -íntima y local- que Saer hace de ella.

Como aquellos exploradores y naturalistas a los que admira y cita en El río sin orillas y otros ensayos -Darwin, Azara o Hudson-, Saer despliega una mirada dinámica y directa del espacio, propia del viajero que lo transita pero que también puede detenerse a contemplar o a esperar que ciertos fenómenos naturales se produzcan. ${ }^{17}$ Incorpora a su vez varios sentidos que exceden el sentido privilegiado de la vista que ponderaba la disciplina en sus comienzos. ${ }^{18}$ La descripción naturalista que Saer aprende de sus maestros se convierte en otra forma de la detención poética y lo obliga a precisar texturas y formas, a diseccionar las partes visibles del objeto, y a recomponerlo utilizando la descripción combinada, recurso también empleado por Azara y otros, que consistía en describir un animal o una planta comparando sus partes con animales y plantas conocidos:

El timbó tiene vainas negras que se parecen un poco a las del algarrobo, pero que son enroscadas y duras. El aguaribay de lejos se parece al sauce, porque su fronda es un poco transparente y cae hacia abajo como la del sauce llorón, pero las hojas son más chiquitas y se presentan en racimos. Tiene un frutito redondo, bien rojo, que cuelga en racimos poco espesos. La vaina del jacarandá es achatada y dura. El timbó es un árbol extendido y petizón. Ya hay paraísos florecidos (20 de septiembre). La tipa es una especie de acacia muy grande. También hay ceibos. Junto con los tres enormes palos borrachos de detrás del convento, y del gran ombú que bordea el agua, hay también pinos y paraísos muy jóvenes que crecen en la barranca, hacia el río (Saer 2013: 286).

En este caso, a la notación escrita, Saer suma un pequeño registro icónico y realiza, sobre el mismo renglón y del mismo tamaño que las letras, tres pequeños dibujos de las vainas descriptas. ${ }^{19}$ La operación naturalista siempre busca saldar la distancia entre la escritura y el despliegue visual de las variedades de plantas y animales encontradas en territorio americano, algo que Marta Penhos ha denominado "el deseo de las imágenes". Sin embargo, Saer no es un pintor ni viaja acompañado de dibujantes, y a excepción hecha por ese pequeño dibujo, es en el interior de sus anotaciones donde atempera ese deseo. Las estampas naturalistas de Saer se presentan a menudo como verdaderas imágenes y remedan lo que Natalia Brizuela caracteriza como "las fichas 
de archivo" de los pintores naturalistas, quienes como en el caso de Hercule Florence, realizaban diseños que se incorporaban junto a las anotaciones del diario de viaje. Su función era hacerle recordar al observador aquello que había visto en algún lugar lejano para que después fuera posible reconstruir el hallazgo. Se trata, como ella señala, de acuarelas que captan una imagen desde un punto de vista único e intentan ser lo más fieles posible al modelo. ${ }^{20}$

Sin embargo, como decíamos al comienzo, algunas de las fichas que ensaya Saer incluyen y desbordan la notación naturalista. El 2 de diciembre apunta en la libreta negra:

LLEGÓ EL COLIBRÍ. A las cuatro y media de la tarde, un poco más temprano que de costumbre. [...] El colibrí -lomo de un verde azulado, metálico, brillante, pecho grisáceo y cola negra separada del resto del cuerpo por una raya casi blancapicoteó durante más o menos un minuto algunas flores en su planta habitual y después se dirigió hacia otra maceta donde había un segundo ejemplar de la misma especie. [...] Yo también lo había visto en años anteriores, en la misma planta, aunque un poco más tarde; también mi hermana se asombra de que hubiera llegado tan temprano. Me pregunto si no adelantó su visita a causa de unas nubes que estaban llegando del este y que parecían anunciar tormenta (Saer 2013: 312).

En primer lugar, la observación minuciosa no es privativa de este tipo de descripción sino que participa de una forma de contemplación que Saer ha ensayado desde los comienzos de su literatura sobre muy diversas manifestaciones del orden material del mundo: los filamentos de la carne, las gotas de sudor del Gato Garay o la mancha que deja el cuerpo aplastado de una araña. Pero además, interesa en este caso cómo el rápido boceto que captura del natural se funde en una experiencia del tiempo que comparte con su hermana y permite advertir que su relación con el colibrí y las flores rojas sobre las que se posa está largamente fundada en muchas otras tardes compartidas. Es decir, la estampa se abre a una dimensión de la cotidianeidad afectiva del escritor y la "autoridad científica" se diluye en los pareceres que comparten Saer y su hermana, ese "saber de los vecinos" y los pobladores que también Hudson recogía con cuidado para amenizar sus catálogos. ${ }^{21}$

En este sentido, cabría entender la descripción naturalista que Saer ensaya en sus libretas como otra versión del modo Saer de la contemplación, vinculada además con un tipo de concentración que ya había experimentado entre fines de los setenta y principios de los ochenta traduciendo haikus. El haiku es, como él mismo apunta en las notas de preparación para La grande, "vividez, epifanía. [...] el residuo de una lucidez momentánea que integra al sujeto en el universo y al universo en el sujeto" (Saer 2013: 370) y como señala Sarlo retomando a su vez a Barthes, constituye otra forma de notación precisa de la naturaleza, de los cambios de temperatura y luminosidad, de la particularidad sonora y cromática de las estaciones o del movimiento del aire.

\section{LAS ESPECIES PREDILECTAS: EL JARDÍN SECRETO DE LA LENGUA}

Como se sugirió más arriba, las libretas forman parte de una "escritura tardía" en la trayectoria saeriana. $\mathrm{Si}$ efectivamente, como propone Dalmaroni en "La vuelta incompleta", el momento de mayor descomposición experimental "negativista" se produce en Nadie nada nunca (1980) y luego la poética de Saer se va atemperando y encontrando las formas de un regreso -a los comienzos, a la ciudad de Santa Fe, e incluso a ciertas variantes de lo típico, el color local y el color de época-, vuelta que se termina de completar en La grande, sería posible comprender la escritura de estas libretas en ese momento de clivaje señalado por el comienzo de la escritura de Glosa (1982) y la publicación de El entenado (1983). ${ }^{22} \mathrm{Al}$ respecto, Premat y Chejfec coinciden en que es a partir de esta novela cuando se produce una reorientación de la producción de Saer que llega para darle un "relato fundador" a la zona y reinventar lo propio: la figura de autor y el lugar de lo narrado. En "Aventura y especulación”, Chejfec ve en El entenado la consolidación de dos variantes que articularán toda la poética de Saer: especulación y geografía. Retomo la cita completa:

Especulación y geografía se afirmaron desde entonces como ejes principales del discurso saeriano. (Podríamos decir también: narración y naturaleza, pero sería generalizar demasiado.) Para Saer la narración es un registro especulativo que se levanta 
sobre el escenario natural; queda establecida una lucha de opuestos: la realidad siempre densa y contradictoria, múltiple, y el deseo de desentrañarla por medio de un relato minucioso y a la vez aproximativo, incapaz (Chejfec 2010: 803).

Interesa particularmente ese paréntesis que a Chejfec le parece quizás demasiado general, porque como intentó mostrarse, las libretas ponen en escena a un sujeto que especula con los saberes de un naturalista aficionado y de un lector de viajes, la naturaleza de la región. Las libretas permiten interrogar en clave empírica los "regresos" al oikos que consumará La grande en clave ficcional y profundizar las relaciones necesarias que se establecen entre viaje e imágenes en novelas como Las nubes y en ensayos como El río sin orillas.

A diferencia de Hudson, que en medio de un estado de fuerte debilidad física puede recobrar las aventuras y vibraciones de su infancia vivida en las pampas sudamericanas: "tuve una clara, continua y maravillosa visión del pasado y me vi tentado [...] a escribir esta narración” (2007: 8), Saer, que desconfía hace tiempo del poder evocativo de la memoria, debe volver físicamente a la zona y registrar con cierto grado de obsesión las formas del habla y las formas de la naturaleza. En este sentido convierte el avatar naturalista en una versión de escritura exiliar y poética, pero no nostálgica. ${ }^{23}$ Lo curioso entonces no es tanto que Saer recolecte las nomenclaturas científicas sino cómo el vocabulario aséptico de la botánica y algunos protocolos de observación y descripción naturalista se vuelven parte de su "lengua privada", agudizando su modo de contemplación y revitalizando su escritura. La "litteraria" de Saer se compone entonces de un tramado de conjeturas, saberes compartidos, recuerdos de infancia, experiencias teñidas de afectividad y evocaciones literarias. La ficha naturalista saeriana, como un haiku, como un fragmento poético, funda un lugar, vuelve reconocible un espacio.

En "Lengua privada y literatura” Saer advierte: "el uso personal de la lengua es el jardín secreto en el que cada uno cultiva las especies de su predilección” (Saer 2006: 38) y sostiene que esa plasticidad para anexar nuevas zonas del lenguaje y la posibilidad de pensar a las palabras como sedimentos de asociaciones y connotaciones personales solo puede darse en el ámbito de la lengua materna. El escritor que, estando en París, habla un perfecto francés con tono santafesino puede, en sus regresos y en un momento de clivaje de su poética, anexar nuevas zonas de la lengua -científica, naturalista y viajera- y cultivarlas en el “jardín privado" de su lengua materna bajo el sol podrido y extranjero de la región. ${ }^{24}$

\section{BIBLIOGRAFÍA}

Brizuela, Natalia (2012). “Capítulo II: O som da natureza, ou escrevendo com luz nos trópicos: Hercule Florence”, en Fotografia e império. Paisagens para um Brasil moderno, San Pablo, Companhia das Letras, pp. 63-105.

Chejfec, Sergio (2010). “Aventura y especulación”, en Saer, Juan José, El entenado - Glosa, edición crítica,Julio Premat (coord.), Poitiers, CRLA; Córdoba, Alción Editora, pp. 802- 807.

Dalmaroni, Miguel (2010). "El largo camino del «silencio» al «consenso». La recepción de Saer en la Argentina (1964-1987)”, en Saer, Juan José, El entenado - Glosa, edición crítica,Julio Premat (coord.), Poitiers, CRLA; Córdoba, Alción Editora, pp. 607-663.

Delgado, Sergio (2013). “Presentación”, en Saer, Juan José. Papeles de trabajo II. Borradores inéditos. Buenos Aires, Seix Barral, pp. 275-280.

Foucault, Michel (2013). "5. Clasificar", en Las palabras y las cosas. Una arqueología de las ciencias humanas. Buenos Aires, Siglo XXI Editores, pp. 141-180.

Gamerro, Carlos (2015). "Hudson y la invención del paisaje" en Facundo o Martín Fierro. Los libros que inventaron la Argentina, Buenos Aires, Sudamericana, pp. 178-189.

Hudson, William H. (2007). Allá lejos y hace tiempo, La Plata, Terramar.

Hudson, William H. (2010). El naturalista en el Plata, Buenos Aires, El Elefante Blanco.

Montaldo, Graciela (2004). Ficciones culturales y fábulas de identidad en América Latina, Rosario, Beatriz Viterbo Editora. 
Patruno, Luigi (2015). Relatos de regreso. Ensayos sobre la obra de Juan José Saer, Rosario, Beatriz Viterbo Editora.

Penhos, Marta (2005). Ver, dominar, conocer. Imágenes de Sudamérica a fines del siglo XVIII, Buenos Aires, Siglo XXI.

Premat, Julio (2009). “Saer: un escritor del lugar”, en Héroes sin atributos, Buenos Aires, Fondo de Cultura Económica, pp. 167-202.

Rodríguez, Fermín A. (2010). Un desierto para la nación. La escritura del vacio, Buenos Aires, Eterna Cadencia.

Saer, Juan José (1997). Las nubes, Buenos Aires, Seix Barral.

Saer, Juan José (1998). “Juan”; "La perspectiva exterior: Gombrowicz en la Argentina” en El concepto de ficción, Buenos Aires, Ariel, pp. 78-84 y 17-29.

Saer, Juan José (2001). Cicatrices, Buenos Aires, Planeta.

Saer, Juan José (2003). El río sin orillas. Buenos Aires, Seix Barral.

Saer, Juan José (2006). "Lengua privada y literatura” y "Sobre Onetti y La vida breve" en Trabajos, Buenos Aires, Seix Barral, pp. 35-41 y 233-242.

Saer, Juan José (2013). “Libretas de viaje”, "El paraíso recuperado”, en Papeles de trabajo II. Borradores inéditos, Buenos Aires, Seix Barral, pp. 273-335 y 28.

Saer, Juan José (2015). Ensayos. Borradores inéditos 4, Buenos Aires, Seix Barral.

Sarlo, Beatriz (2007) [1996]. "La duda y el pentimento", en Escritos sobre literatura argentina, Buenos Aires, Siglo XXI, pp. 269-277.

Sarlo, Beatriz (2016). Zona Saer, Santiago de Chile, Ediciones Universidad Diego Portales.

Van Den Abbeele, Georges (1992). "Introduction: 'The Economy of Travel'” en Travel as metaphor. From Montaigne to Rousseau, Minneapolis, University of Minnesota, pp. XIII-XXX.

\section{Notas}

1. En sus cuadernos pueden encontrarse referencias a un viaje por Venezuela y anotaciones sobre su estadía en distintas ciudades europeas, principalmente Toledo. También apunta los nombres de varias regiones francesas que lo muestran recorriendo el país desde la costa este (Isla de Ré, Nantes, La Rochelle) hasta la zona fronteriza de la ciudad de Mulhouse.

2. En 1968 Saer viaja a París con una beca para estudiar el Nouveau roman y desarrolla su carrera como escritor en el exterior. Después de una fugaz visita a Argentina en marzo de 1976, no volverá sino hasta 1982, fecha en la que comienza la escritura de sus libretas. A partir de allí, regresará periódicamente al país.

3. Solo una parte de estos cuadernos fue previamente publicada. Como se sabe, Saer separó y mecanografió las "Notas en vivo (sep-oct. 1982)" para la composición de Glosa, incluidas en el dossier genético de la novela en la edición crítica coordinada por Julio Premat. Diversos críticos se han referido a estas notas al considerar la novela y en particular Luigi Patruno, en Relatos de regreso. Ensayos sobre la obra de Juan José Saer, ha hecho un estudio separado de ellas en el que las considera como "otro" libro que podría figurar autónomamente en la obra de Saer, al explorar la veta íntima que se desprende de una escritura aparentemente impersonal, que perfecciona ese "desmontaje autoral" ya practicado por el escritor con anterioridad.

4. En general se ha enfatizado el carácter "imaginario" y ficcional de la "zona" como un espacio eminentemente "literario". El mismo Saer se ha encargado de privilegiar esta lectura y ha señalado en su ensayo sobre Onetti: "el territorio en el que un narrador instala sus ficciones, solo tiene un parentesco lejano con el espacio o la geografía habitados por los seres de carne y hueso que chapaleamos en lo empírico" (Saer 2006: 240-241). Sin embargo, cuando Julio Premat, en "Saer: un escritor del lugar", se interroga por la "zona”, retoma los documentos preparatorios para la escritura de Glosa o La grande, entre los que encuentra las libretas de viaje a Santa Fe repletas de anotaciones sobre el clima, la vegetación y los modos de hablar, e identifica esa vertiente evidentemente referencial que había quedado un poco soslayada, un "parentesco" entre el territorio de las ficciones y el espacio de Santa Fe y sus alrededores que, señalará Premat, aunque pueda ser "lejano”, aumenta en las obras posteriores del autor.

5. Carl Von Linneo (1707-1778) se formó como científico, médico y botánico en Suecia y Holanda y formuló su sistema en tres obras claves: Systema naturae (1735), Fundamenta botánica (1736) y Classes plantorum (1738). Allí estableció los fundamentos para el esquema moderno de la nomenclatura binomial (que caracteriza a los seres vivos según dos nombres, el nombre del género y el nombre específico) y que fue inicialmente pensado para el reino vegetal y luego adaptado por Linneo para el reino animal. A mediados del siglo XVIII era reconocido como el principal naturalista de Europa. Su sistema fue muy difundido por la gran cantidad de discípulos que viajaron por distintas partes del mundo con el fin de 
recolectar muestras y especímenes. Como señala Penhos (2005), las ideas y debates que se produjeron en el terreno de la historia natural en Europa repercutieron profundamente en la obra de los demarcadores en Sudamérica.

6. Es preciso aclarar que luego relativizará esta clasificación entre lectores europeos y argentinos o entre especialistas y profanos para terminar señalando que su libro "no se dirige a ningún lector en particular" (Saer 2003: 20) aunque por momentos se detenga a explicar algunos términos específicos, como el de "boleadoras", "para el lector idiota -que puede ser también rioplatense-” (48) o precise distancias geográficas entre pueblos de Santa Fe.

7 Esto puede observarse en la clasificación ideada por Linneo, para quien cualquier animal podía ser descripto a partir del siguiente orden: nombre, teoría, género, especie, atributos, uso y, para finalizar "litteraria”. Es decir, todo lo que se había dicho, se imaginaba y fabulaba sobre ese ser vivo quedaba desplazado hasta el límite de la clasificación.

8. Este gesto de nominación, como se adelantó, se acerca además al de los viajeros naturalistas que recorrieron el territorio sudamericano durante los siglos XVIII y XIX y se vinculará con esa autofiguración que el escritor irá construyendo en sus textos de regreso al país en tanto "naturalista amateur".

9. Aunque puede entenderse, claro, que al menos ciertos fragmentos de las libretas funcionaron como el espacio de trabajo y de acopio de vocabulario que después incluiría en los textos editados como El río sin orillas.

10. En "tormentas de alguaciles", uno de los apartados de El naturalista en el Plata y también en Allá lejos y hace tiempo, Hudson presenta a estos insectos a partir de un dato curioso, que es el mismo que recoge Saer en sus libretas: "Los grandes alguaciles aparecen en el verano y en el otoño; no con el viento, sino precediéndolo y lo más extraño es que no se los ve en toda la región hasta ese momento" (Hudson 2010: 109-110). En esta y otras descripciones puede observarse el sutil tratamiento poético de su observación naturalista. Hudson exalta la extrañeza de una de esas especies, todas "de un vivo color escarlata" (109) y las compara con "un geranio rojo que brotara en un campo desprovisto de flores" (109); dialoga con otros naturalistas para explicar su singular comportamiento e incorpora finalmente una anécdota que le "refirió un inglés que residía en el Río Negro" (111), que le aporta dinamismo a la descripción y confirma sus propios hallazgos.

11. En este linaje de poetas-naturalistas, resulta sugerente la siguiente afirmación de Beatriz Sarlo en "La duda y el pentimento": "La naturaleza de la región, Ortiz la describe con esa lengua de herborista, de mirador de pájaros y de miniaturas, que es lo opuesto al pintorequismo congelado del regionalismo arqueológico" (2007: 274).

12. En varias oportunidades Saer se refiere a la poética de Juan L. Ortiz, para quien el "paisaje" no constituye un determinismo geográfico o regional sino una interrogación deslumbrada ante la proliferación material de la naturaleza, muy afín a la experimentada por el propio Hudson: "Para la poesía de Juan el paisaje es enigma y belleza, pretexto para preguntas y no para exclamaciones, fragmento del cosmos por el que la palabra avanza sutil y delicada, adivinando en cada rastro o vestigio, aun en los más diminutos, la gracia misteriosa de la materia” (Saer 1998: 82).

13. Saer habla con orgullo de su voluntaria vida al margen del mainstream literario parisino y Sarlo comenta en Zona Saer que a pesar de manejar perfectamente la sintaxis y el léxico francés, elige hablar "con una tozuda fonética santafesina" (2016: 53). Montaldo enfatiza el carácter excéntrico de la escritura de Hudson que, desarrollada en el contexto de la literatura del imperio (Conrad y Kipling) emerge como una voz excéntrica que basa sus ficciones en la naturaleza y el recuerdo de una antigua patria. Pero a su vez el propio Hudson es un excéntrico en Londres, pobre y ajeno a una cultura que no termina de asimilarlo y debe aprender a dominar el inglés como lengua extranjera. Hudson habla un "mal inglés" y "cuando se tiene que enfrentar a la identidad deseada (la inglesa) surgen las diferencias y debe establecer su lugar subordinado en una sociedad en la que no hay sitio claro para él” (Montaldo 2004: 129).

14. Retomo esta idea de Graciela Montaldo, quien caracteriza el particular naturalismo practicado por William H. Hudson. En primer lugar, es un científico amateur capaz de participar a la vez tanto de las emergentes revistas científicas de la época como de esa "literatura menor" que recogía experiencias de contacto con la naturaleza (actividad 'naturalista' de muchos ciudadanos, composiciones escolares cuyo tema era la vida silvestre). En segundo lugar, se reapropia del discurso científico como si se tratara de un "saber personal" basado en la observación directa o en los testimonios recogidos 'directamente' en el territorio, y menos en los libros, aunque, por supuesto, Hudson dialogue con otros naturalistas en sus trabajos, y también lo haga Saer. Se trata además, en ambos casos, de escritores cuyas observaciones se localizan en territorios íntimos. Señala Montaldo a propósito de Hudson: "sus reflexiones [...] sobre la naturaleza [...] son también una suerte de 'viaje interior', a medias científico, a medias místico, para tratar de responder preguntas sobre la subjetividad” (2004: 125).

15. Fermín Rodríguez distingue diferentes formas de la práctica naturalista, por un lado aquella llevada a cabo según los tiempos del progreso científico y regulada por las instituciones y los estados que pagaban las exploraciones, como en los casos de Darwin y Humboldt y por el otro, aquella ensayada por Hudson en sus "días de ocio", como una forma de perder el tiempo y vagabundear, aun cuando el resultado de esos paseos fueran "inútiles investigaciones". Entre la observación científica y la experiencia personal, Hudson practica, señala Montaldo, una ciencia desinteresada que se presenta como un lugar de fractura del saber que desestabiliza la autoridad científica incorporando el conocimiento de vecinos y pobladores. 
Saer, podría pensarse, anota lo que le interesa, no hay sistematicidad en sus libretas sino más bien una mirada que apunta lo que se cruza en su camino de forma un poco aleatoria y que se encuentra varias veces observando - "improductivamente"- lo mismo.

16. Como ejemplo puede observarse la siguiente anotación, que Saer incorpora a modo de lista: "Surubí: fin de septiembre a fines de abril. Dorado: fin de septiembre a fines de abril. Amarillo: invierno. Moncholo: toda época” (2013: 292).

17. Marta Penhos también verifica esta doble posibilidad en la mirada de los expedicionarios y advierte por ejemplo que Félix de Azara desplegaba, por un lado, una visualidad dinámica que le permitía captar la realidad viva de los animales y plantas en su hábitat, pero también una mirada minuciosa que se fijaba en ciertos objetos y era capaz de precisar la ubicación geográfica de cada especie, sus medidas, proporción, color y particularidades morfológicas: “el dato preciso y la observación aguda se insertan en el relato, actuando como anclaje científico de la experiencia del viajero” (2005: 208).

18. "Al llegar a la vereda roja, más ancha, que bordea el convento empieza a oír de la palmera y los pinos que se elevan en medio de los canteros de césped, un canto de pájaros múltiple y sostenido" (Saer 2013: 294).

19. Podría establecerse un vínculo entre la descripción que disecciona las partes visibles del timbó y el pequeño dibujo incluido por Saer con las principales características del dibujo botánico, en el que usualmente se dibujaba la planta entera con su raíz, tallo y hojas en el centro de la página y al costado se disponían las flores y frutos. Ese era el modelo visual que se seguía para representar la taxonomía de Linneo, que tuvo una gran difusión por toda Europa y llegó a España con las publicaciones de la obra linneana.

20. Estas fichas o diseños construidos por los pintores y dibujantes naturalistas seguían instrucciones precisas sobre cómo captar medidas y colores del natural. La Historia Natural de Buffon, seguida en gran medida por Félix de Azara, le otorgaba una gran importancia al registro icónico y creía que una buena descripción debía captar "el todo" de un ser vivo.

21 Saer también pinta con los colores de la literatura: "Cuando está un poco crecido, el río es azulado, idéntico color que en el río de la Plata ('era azulejo entonces como oriundo del cielo')” (2013:282). Incorpora aquí la variación borgeana del azul del poema "Fundación mítica de Buenos Aires".

22 En relación con este carácter tardío de las libretas y la reorientación del proyecto saeriano, se debe recordar también que es precisamente en la década del ochenta cuando la figura de Saer comienza a ser reconocida hasta su consagración en el 2000. Como explica Dalmaroni en “El largo camino del 'silencio' al 'consenso'. La recepción de Saer en la Argentina (1964-1987)" por lo menos hasta principios de los ochenta, la literatura de Saer careció de un gran reconocimiento y no pudo ser del todo asimilada por los distintos actores del campo literario.

23. A diferencia de Hudson, que inscribe su experiencia de la pampa sudamericana como un intento por conservar algo de esa naturaleza primitiva pero en vías de desaparición que conoció en su infancia, Saer no es nostálgico. En múltiples textos y entrevistas desarticula las ideas de regreso y de patria. En "El paraíso recuperado" (1969) desarma el tópico de la nostalgia porque a pesar de evocar, desde París, el mundo de Santa Fe, cuando regresa a su casa natal se pregunta "¿qué otro lugar habrá en el mundo, para que yo quiera - un nudo de deseo y de nostalgia- estar en él y no aquí?” (Saer 2013:28). En un borrador de entrevista puntualiza su idea sobre la patria, denunciando que bajo esta abstracción se esconden las peores atrocidades de la historia, y ofrece su particular definición de una patria material, experiencial e íntima: "La materialidad de la patria se confunde con mis experiencias y está constituida por la existencia precisa de paisajes, caras, nombres, experiencias comunes. [...] Por eso a veces me sé decir que todo regreso es imposible, ya que esa patria que nos parece persistir en el espacio no es otra cosa que una experiencia intensa vivida en un pasado irrecuperable" (Saer 2015:150).

24. En varias ficciones el sol es extranjero. Así aparece por ejemplo en la memoria de viaje que escribe el doctor Real: "me pareció [...] que éramos la única cosa viva retorciéndose bajo ese sol extranjero, aplastante y desdeñoso” (Saer 1997:175). Así empieza también Cicatrices: "Bloque, qué va a ser un bloque, esa luz de porquería: no sé de qué sol podrido puede estar llegando” (Saer 2001:10). 